\title{
Rosália Sandoval, o tempo não te esquece e nós te resgataremos
}

Luciana Fonseca M. de Lemos'

Rosália Sandoval, escritora alagoana que viveu na primeira metade deste século, dedicou sua vida à produçào literária. Escreveu textos nos gêneros prosa e poesia. Embora tivesse, por algum tempo, um espaço conquistado, ou seja, um relativo sucesso como poeta e tradutora, morreu desconhecida. Sendo assim, pergunto, da mesma forma que Constância Lima Duarte (1996) faz em seu artigo sobre estudos de mulher e literatura: "por que tantas escritoras conheceram um certo sucesso em vida e, depois, cairam no esquecimento geral? Por que seus poemas, romances, peças teatrais deixaram de ser citados, encenados e transcritos em antologias e manuais literários, apesar de todo seu valor?"(p.31).

Mesmo tendo publicaçòes em quantidade razoável - totalizando doze obras -, Rosália nào era tào bem conceituada quanto seu irmào Sebastiào de Abreu que, sem haver publicado um único livro, já era patrono da cadeira número 25 da Academia Alagoana de Letras, em 20 de janeiro de 1883. Após sua morte é que a obra Angelus - tão notada pelos críticos por suas "qualidades estilísticas" e por seu prodigioso mérito - foi organizada para publicaçào por sua irmà.

As obras de Rosália, infelizmente, nào constam da Academia Alagoana. Mas sua contribuiçào literária na sociedade foi bastante conhecida, como é o exemplo do depoimento dado pelo escritor Graciliano Ramos que, numa entrevista publicada no Jornal de Alagoas em 18 de setembro de $1910^{1}$, fala sobre o que pensava da literatura e das belas artes em Alagoas:

Nào devemos ser muito otimista, nem demasiado pessimista. É verdade que Alagoas nào é um Estado extremamente fecundo em literatura, mas temos vários alagoanos que fazem figura nas letras. [...]

\footnotetext{
Mestranda em Literatura Brasileira na UFAL, iniciou-se na pesquisa em 1994 como bolsista de Iniciação Científica com a Prof". Dra. Izabel Brandão, coordenadora do projeto "Literatura de Mulheres em Alagoas". Foi a partir dai que obteve o primeiro contato com alguns textos de Rosália Sandoval publicados na imprensa local.

I Texto gentilmente cedido pelo escritor alagoano e critico literário Marcos de Farias Costa, cuja fonte se encontra reeditada por Moacir Santana em A face oculta de Graciliano Ramos, Seculte, 1992.
} 
Creio que nào devemos deixar na penumbra os vultos de Fernandes Tavares, Franco Jatobá, Rosália Sandoval, Rodrigues de Melo, Motta Lima, Rosalvo Ribeiro, etc. [...]

Se Alagoas não é um Estado predestinado, nào é para admirar, porque as letras e artes em nosso país nào estào muito desenvolvidas. Está muito proporcional nosso adiantamento com o do resto do mundo. (p.39)

Ainda nesta entrevista, Ramos discorda dos meios que a Academia vinha utilizando para desenvolvimento literário em Alagoas. Ele diz:

- [...] Nào sei onde está a vantagem de haver uma Academia de Letras em Alagoas. Será uma associaçào que nào trará desenvolvimento algum à literatura do nosso Estado. Sempre o espírito da imitaçào! Uma Academia, em Alagoas, não será mais que caricatura da Academia Brasileira de Letras. E o resultado? Teremos meia dúzia de "imortais" que, escorados em suas publicaçòes de 200 páginas, olharào por cima dos ombros os amadores que estiverem fora da panelinha acadêmica. (p.43)

Para se ter uma idéia do que Rosália produziu, além do Curso elementar de português (1921), foram publicados versos, contos, ensaios, crônicas, fábulas, anedotas, prosa poética intimista, crítica literária ${ }^{2}$, histórias de Lampiào e traduções, bem como algumas de suas memórias em dois volumes.

Enquanto isto, treze anos após a morte de Sebastiào de Abreu, escreve o crítico Jurandir Gomes uma carta ${ }^{3}$, falando da necessidade de se incluir poemas deste escritor em um livro de coletâneas, já que o escritor precisava ser lembrado por seu talento e por haver morrido jovem. Nesta carta, o autor diz:

\footnotetext{
"No segundo trabalho desenvolvido durante a pesquisa "Literatura de Mulheres em Alagoas", analisei cinco textos em prosa de Rosália Sandoval de 1901 a 1933, os quais representam fortes características do eclético estilo literário da autora, tendo como topo a crítica literária propriamente dita.

${ }^{3}$ Além do livro Coletânea de poetas alagoanos, de Romeu de Avelar, esta carta é o único documento encontrado na Academia Alagoana de Letras em que é citado o nome da escritora Rosália Sandoval, cedido pelo presidente desta Academia, Sr. Carlos Moliterno. Mesmo assim, não consta data, nem a quem é referida.
} 
Rosália Sandoval homenageou a memória de seu irmão Sebastiào de Abreu, publicando-lhe a obra inacabada ANGELUS. Num prefácio de poucas linhas, diz-nos algo sobre esse jovem talentoso, que aos treze anos de idade era prosador e aos vinte e seis morria escrevendo versos - versos chegados até hoje, ainda despertando gratas emoções em quem os lê, em quem os ouve.

Sebastiào de Abreu necessitava de ser lembrado.

Rosália, mesmo com dificuldades, lutou pelo seu maior objetivo: escrever e registrar suas impressòes de vida. Nào se contentando com seu trabalho local lecionando, publicando livros e contribuindo para os jornais -, ela resolve ampliar seus horizontes. Hoje, sabemos que pesquisadoras como Izabel Brandào, Yasmin Nadaf, Elizabeth Siqueira, Luzilá Ferreira, Zahidê Muzart, Constância Duarte e outras, vêm resgatando escritos da assim chamada "literatura escrita por mulheres", o que permite achar, em meio a outras 'sonhadoras', alguns textos esquecidos de Rosália Sandoval.

Em Um discurso feminino possível, professoras de Pernambuco, ao escreverem sobre as pioneiras da imprensa, mencionam Rosália Sandoval como colaboradora do jornal $O$ Lyrio. Em Sob o signo de uma flor, Yasmin Jamil também encontra alguns textos dessa Autora publicados na imprensa do Mato Grosso. E em Alagoas, pesquisadoras do grupo "Literatura de Mulheres em Alagoas" vêm, conjuntamente com Izabel Brandào, coletando textos de escritoras como Júlia Lopes, Celeste de Pereira, Paula Achilles, Rosália e outras, publicados em periódicos locais.

De Norte a Sul, Rosália nào se limitou a um espaço restrito. Ela queria mais: queria ampliar seu percurso dentro da ordem estabelecida. Com isso, a escritora procurava diferenciar-se das restriçòes que muitas mulheres sofriam e, como professora, ela própria dizia que educar para a vida não bastava. Como disse Constância Lima Duarte (1996), a educaçào da elite feminina constava de "aulas de catecismo, de costuras, da arte de agradar, de como se compor bem e de como se fazer reveréncias"(p.25); tudo "resumia-se mais numa preparação mundana que em educalyăo propriamente dita" (p.25), e servia como obstáculo para que mulheres começassem a escrever. Mas foi necessário que mudanças ocorressem, uma vez que elas precisavam, também, ocupar-se da educação de seus filhos, argumento este tão defendido por Júlia Lopes de Almeida .

"Cf. "Escritoras em Alagoas: uma análise de textos em prosa do início do século" In: Revista Leitura, da UF.AL, 1996. (p. 109-133) 
Através do texto "O livro", publicado em 1925 no Jornal Correio da Pedra, Júlia Lopes diz encontrar nele a "fonte inesgotável do possivel conhecimento" e único amigo, onde se pode "pedir amparo numa hora de desalento e conselho, num momento de dúvida" (p.116). Neste ensaio, Júlia ainda diz que a leitura é o ponto de referência onde a mulher habilita-se a conservar, dirigir e instruir seus filhos. Argumento este tão bem utilizado para direcionar a mulher, que tinha permissão para se dedicar apenas ao "lar" e às letras.

Da mesma forma, Rosália valorizava a literatura e a escrita como ato inerente à condição humana, e colaborava com a educaçào de suas alunas nas principais províncias, dedicando-lhes seus escritos, incentivando-as a escreverem e a transpor sua idéias para o papel, mas de forma diversa das idéias que estas instituiçòes defendiam: de que mulheres permaneciam ou permaneceriam inferiores intelectualmente. Rosália Sandoval permanecia inerente à literatura, cada vez mais motivada escrever.

Segundo Guacira Lopes Louro (1997), em "Mulheres na sala de Aula",

A identificação da mulher com a atividade docente, que hoje parece a muitos tão 'natural', era alvo de discussões, disputas e polêmicas. Para alguns parecia uma completa insensatez entregar às mulheres usualmente despreparadas, portadoras de cérebros 'poucos desenvolvidos' pelo seu 'desuso' a educaçào das crianças ${ }^{5}$ (p.450).

A partir daí, argumentos opostos passaram a ver o magistério como extensão da maternidade, já que havia uma incompatibilidade do trabalho com o casamento, e a mulher deveria optar. E, como se nào bastasse, a sexualidade das professoras despertava interesse para curiosos, principalmente das solteiras e viúvas.

Constância Lima Duarte (1996) diz que para "estudarmos escritoras é preciso considerar sempre a classe social a que pertencem"(p.29). Ela observa que as "mulheres de uma ou outra cultura são mais livres" $(\mathrm{p} 29)$. Assim, analisando o contexto social e a condição em que Rosália viveu, é possível constatar um relativo preconceito sofrido por sua condição de mulher provinciana, mestiça, solteira e pobre. Certamente essas não eram qualidades de alguém a quem se pretende confiar a educaçào dos filhos. Muito menos quando esta vem transferida sozinha para a Capital do Rio de Janeiro.

'LOURO, Guacira Lopes. "Mulheres na sala de aula" In: História das mulheres no Brasil. São Paulo: Contexto, 1997. 
A importância da origem ou condiçào social era tão forte na sociedade alagoana que ela nào se referiu ao trabalho de Rosália como um todo. Temos como exemplo a citaçào feita por Raimundo de Meneses em Dicionário Literário de Letras, quando declara que Rosália era apenas filha do major, irmã de Sebastião, pobre e morreu já idosa. E, sobre sua obra, recebe mais um acréscimo em Coletânea de poetas alagoanos pelo crítico Romeu de Avelar, dizendo que Rosália era reconhecida por haver traduzido um livro de escritores estrangeiros que na época teve repercussào. Assim diz:

Rosália Sandoval

Pseudônimo: Rita de Sousa

Nasceu em Maceió - data ignorada.

Filha do Major Felício Santiago de Abreu e D. Epifânia de Pontes Abreu. Irmà do poeta Sebastião de Abreu. Sua família era paupérrima. Idosa mudou-se para o RJ. Faleceu no Rio de Janeiro aos 80 anos, na Estação São Francisco Xavier, Sextafeira da Paixão de 1956.

Bibliografia

Através da Infância (1918)

Quando as Roseiras Floriram (versos)

Gingo (poemeto) e volume de traduçòes de Poetas Americanos.

No livro intitulado Versos Alheios, publicado em 1930, Rosália Sandoval reúne poesias de setenta escritores latino-americanos, entre eles uruguaios, argentinos e chilenos, onde ela faz um comentário de cada autor e sua obra, a fim de sustentarse a favor de uma pátria única. Este foi o seu pensamento e maior propósito pronunciado no prefácio do volume. Nele, a Autora argumenta ser uma pátria o prolongamento de outra, e que, para isto, nào precisaria haver fronteiras. Compreendidos pela autora como irmàos, ela leva o leitor a pensar que "a igualdade, muitas vezes, quebra a linha da estética" (p.7).

Enfatizando a importância da diferença - substância esta encontrada ao longo dos poemas -, os/as autores/as estrangeiros/as se inspiraram em temas como montanhas, lendas, canções, exílio e o universal amor. Rosália compara a influência do meio físico (pátria como objeto inspirador) com a estilística (a concretizaçào desta inspiraçào em forma poética), o que levaria outros povos a se identificarem com essa relaçào: 
A forma existe por toda a parte - nos ensina o desenho - a cor, porém, é que a torna visível; distingue-a portanto. Mas a cor, todos sabem, não é propriedade de nenhum corpo e, sim, da luz, dessa luz misteriosa que tantos segredos guarda, até o da sua própria substância. [sic] (p.8)

Nesse sentido, Rosália também faz analogia aos povos: 'Um acidente físico tornouos diferentes, operando a distinção entre uns e outros; tal como a luz distinguindo os objetos sem thes alterar a forma" (p.8). Assim, a Autora fortalece a importância da diferença de dialetos, transformada em uma linguagem universal através da literatura. Afirma ela:

Se todas tivessem a mesma graça, o mesmo encanto natural(...); se todos os territórios recebessem a luz do sol com intensidade igual...que monotonia seria a terra! As mesmas paisagens, os mesmos produtos industriais e agrícolas, nào só trariam a insipidez, como também estacionamento e, quiçá, aniquilamento. (p.8)

No meio áureo da exaltação de pátria, nào posso deixar de enfatizar a ousadia da escritora em publicar este prefácio com um só objetivo: a unificaçào, que hoje vem sendo discutida como globalização. Foi através dos versos "alheios" que Rosália planejou burlar o ufanismo de sua época em uma visào mais ampla do mundo. Mesmo assim, ela passou neste texto a incerteza do risco:

nào é, quiçá, temeridade neste nosso tempo de transiçào, falar desassombradamente sobre pátrias; mas o é talvez, falar sobre versos, e, ainda mais, apresentar ao público um livro que se ocupa de poetas estrangeiros, embora sejam eles verdadeiros trovadores (p. 9).

Utilizar-se dos recursos da língua para expressar seu pensamento, foi o modo que Rosália encontrou para abraçar seus ideais: "Que os nossos ideais se abracem, como se estão entrelajando as nossas liras. Que a confraternizajăo termine essa obra sublime do engrandecimento das pátrias, da sua unificação". (p.10)

Rosália Sandoval nào só participou desta busca, como também dedicou-se a escrever, diferentemente do que o movimento de vanguarda buscava. Com esse objetivo, ela faz um prefácio bastante argumentativo sobre o que seja esta uniào 
cultural. Sào muitas as temáticas escolhidas, selecionadas e traduzidas pela Autora: lendas infantis e indígenas, descriçào local, solidào e amor.

Nesta coletânea, além da predominância de poesias de autoria masculina (49 poetas), encontramos poemas de 21 escritoras como Gabriella Mistral, Sarah Bollo, Maria Bergueristain, Delmira Agustini, Alicia Porro Freire, Maria Clotilde Moratorio de Torres, Alfonsina Storni, Airédides Emoyan, Olga Acevedo de Castillo, Ainda Moreno Lagos, Glorinda Paganini, Maria Cruz Diaz Velis, Antonia Artucio Ferreira, Maria Izcua Barbal Ximenez, Antonia Togores de Munar, Margarita Abelle Caprile, Maria Tereza L. de Saenz, Violeta Branca Cerfoglio Boero e Felisa Lasola.

Neste livro Rosália faz uma homenagem à intelectualidade feminina do Uruguai, apresentando poesias de Luisa Luisi e Juana de Ibarbourou, sendo esta última laureada no México sob o título de Joanna de América, no qual foi homenageada com uma lira de platina, ornamentada com brilhantes.

E quando Rosália veio a falecer, nem mesmo houve alguma homenagem em reconhecimento a sua luta e dedicaçào à produçào literária. Já se passaram mais de 40 anos, e pergunto, nào há mais nada que se possa fazer? Falar de suas obras já é um começo, mesmo que falemos daquelas que possivelmente nào mais existam. $\mathrm{O}$ que sei é que sua maior meta era escrever sobre coisas vitais que fossem capazes de influenciar o mundo. Diferentemente do que o cânone pregava, Rosália pertencia a uma classe de escritoras que lutaram por fortes ideais de vida e que, mesmo não tendo sido elogiada por "escrever como homem" - como diz o mestre Graça sobre Raquel de Queiroz (apud Constância L. Duarte, 1990) -, conquistou seu espaço e respeito junto aos próprios escritores de sua terra natal, como é o caso do crítico literário Romeu de Avelar. Este, identificando o trabalho de Rosália ao longo de meia década, pede que the envie alguns de seus textos para que possam ser incluídos numa coletânea de poetas alagoanos. E Rosália, brutalmente esquecida, velha, triste e possivelmente infeliz, escreve-lhe uma carta dizendo:

Deve ser terrivelmente desagradável a pessoa falar de si mesma e com lealdade que o caso exige. Pelo menos é o que sinto no meu íntimo. Nào encontro, dentro ou fora de mim, algo para dizer que interesse ao público ledor. Dizer que sou velha? Que nasci no bairro mais pobre da capital alagoana? Que sou filha de pais pobríssimos e humildes? Tudo é demasiado conhecido e nào interessa a ninguém, muito menos às Musas [sic]. (p.76) 
Agora, bem diferente se encontra seu tom de voz: não mais a menina que sonha com ideais, nào mais a menina que vibra pela pátria; nem mesmo conta anedotas ou chora pela criança que sofre. E, respondendo à pergunta feita no início do artigo, tentando saber o porquê do esquecimento de escritoras que tiveram suas vozes silenciadas, Rosália foi mais uma vítima do sistema patriarcal. Tentou escapar da subordinaçào de uma sociedade que definia os textos de mulheres como "ninharia, nulidade ou vacuidade, sonho e devaneio' . Agora, sem se preocupar com o reconhecimento ou com o que fala, Rosália, a escritora, nào mais encanta, nem vibra, apenas resiste ao tempo.

\footnotetext{
"Telles, Norma. "Escritoras, escritas, escrituras". In: História das mulheres no Brasil. Contexto,1997. 


\section{Referências bibliográficas}

ABREU, Sebastiào de. Angelus. Rio de Janeiro: ed.?, [ca.1920].

AVELAR, Romeu. Coletânea de poetas alagoanos. Dep. de Ciência e Cultura SENEC: Imp. Oficial, 1970.

BRANDĀO, Izabel. "Literatura de Mulheres em Alagoas". Alagoas, mimeo, 1996.

DUARTE, Constância Lima. "Estudos de mulher e literatura: história e cânone literário" In: Anais do VI Seminário Nacional Mulher e Literatura. Rio de Janeiro, 1995.

. "Literatura feminina e crítica literária". In: A mulher na literatura. Vol I, BH: UFMG/AMPOL, 1990.

LEMOS, Luciana. "Escritoras em Alagoas: uma análise..." In: Revista Leitura da Pós-Graduaçào da UFAL, nº 18,1996.

. "Do ensaio à crítica em textos de Rosália Sandoval". Alagoas: mimeo, 1997.

MENEZES, Raimundo de. Dicionário literário brasileiro. 12. ed. Rio de Janeiro: Livros técnicos e cientificos, 1978.

NADAF, Yasmin Jamil. Sob o signo de uma flor: Rio de Janeiro: Sette Letras, 1993.

REVTSTA da Academia Alagoana de letras. Maceió: Sergasa,1977. Ano III.

TELLES, Norma. "Escritoras, Escritas, Escrituras". In: História das Mulheres no Brasil. Sào Paulo: Contexto, 1997.

LOURO, Guacira Lopes. "Mulheres na sala de aula". In: História das Mulheres no Brasil. São Paulo: Contexto, 1997.

SANDOVAL, Rosália. Versos alheios. Versos Alheios. Rio de Janeiro, Alba: Oficinas Graphicas, 1930.

Curso Elementar de Português - Em Pequenos Exercícios Práticos. Viçosa, Alagoas: Typ. Econômica, 1921. 
SANTANA, Moacir Medeiros de. A face oculta de Graciliano Ramos (Os 80 anos de um inquérito literário). Maceió: Seculte, 1992, p.38-43.

SIQUEIRA, Elizabeth. Um discurso feminino possivel. Recife: Ed Universitária da UFPE, 1995.

TELLES, Norma. "Escritoras, escritas, escrituras". In: História das mulheres no Brasil. São Paulo: Contexto, 1997. 